\title{
Cyber Fasting: A Technique for Digital Peace
}

\section{Gulshan Gupta}

University School of Mass Communication, Guru Gobind Singh Indraprastha University, Delhi, India

Corresponding author: gpreit07@gmail.com

Received: 09 Jan., 2019

Revised: 15 Apr., 2019

Accepted: 22 May, 2019

\begin{abstract}
This paper introduces the innovative idea of Cyber Fasting. It flags some facts about the extreme use of different digital platforms and proposes to be a literate user of digital media and establish digital peace through practicing Cyber fasting. In today's world when we rarely have time to look at our own self, here is an opportunity for something rewarding. As internet use grows, so do its benefits and the risks. The Asian region accounts for the highest number of internet and mobile cell phone consumers among the regions of the world. As the use of information and communication technology becomes more and more widespread, the addiction to cyber media and misuse of such technology have become a concern. Data provided in a report by Jessica Dillinger, Senior Writer, World Atlas (2019) indicates that China and India have the most internet users in the world. In the context of the phenomenon of increasing users of internet and cyber media addiction this paper flags suggestions and ideas to reduce the time people spend doing trivia on social media and the ill effects of cyber media. The remedial suggestions and ideas are for all age groups right from teenagers to old people. This will help in establishing peace not only at homes and workplaces or at the interpersonal level but it will also at the individual level help people to experience inner peace and tranquility. In addition, media literacy skills can also be enhanced.
\end{abstract}

Keywords: Cyber fasting, Cyber media literacy, Internet addiction, Digital peace

We live in a world where many of us are getting increasingly obsessed with different tools of communications. Media use is reaching new levels of intensity. Digital devices are everywhere; from using computers at school, to watching TV at home or playing games on a smart phone. People spend more time than ever watching videos, browsing social media and swiping their lives away on their tablets and smart phones. A report in Live Mint (2018) says that Smartphone usage has gone up by leaps and bounds in India due to increased connectivity in rural areas, coupled with cheaper data plans.

The ubiquitous nature of the media today, especially the cyber media means our continuous engagement with these media. Be it in homes, bedrooms, buses, railways, offices, while walking and even eating- many of us find ourselves busy texting or liking someone's post in the social media. More often than not we find people getting addicted to them and can't live without them. Increasingly we find ourselves in a situation where our lives and time are virtually enslaved to these forms of communications.

Notwithstanding the benefits that accrue from the use of these forms of virtual communication where we can connect to people far and near, many of us due to the addiction instead of spending quality time with our families or in creative pursuits end up spending our precious moments in texting trivia. Many of us have forgotten the value of listening to our inner voice, vacant and pensive moods to stand and stare at the beautiful nature as we are busy with the keyboard of our gizmos. Excessive 
use of social media also affects social relationship in real life. The Internet has transformed the way we communicate, learn, and network, with implications for our broader social, psychological, and physical health and well-being.

We all know that man is a social being but today we are more virtually social. Different social media platforms snatching our social time by showing many new virtual endeavors and forcing each of us to become virtually social instead of becoming actually person to person social. The internet is bringing people together virtually but pushing them away physically.

While the internet connect more people online, it makes people more isolated socially, because the more time they spend online, the less time they spend interacting with people in real life.

A new study by market-research group Nielsen (2018) indicates that American adults spend more than 11 hours per day watching, reading, listening to or simply interacting with media. The report says that the time people spend online has increased significantly over the last four years.

The purpose of this paper is to highlight the need for proactive media literacy initiatives that promote the ethical and responsible use of cyber platforms and social use of technology. In this context the following are the objectives of the study.

\section{Objectives}

$\odot$ To identify the habits of the digital media users.

$\odot$ To identify the effects occurring from digital addiction.

$\odot$ To suggest solutions for Cyber de-addiction.

$\odot$ To promote digital literacy and peace.

\section{Data Collection and Analysis}

The researcher has collected the data for the study from the primary and secondary sources. The analysis of secondary data allows researchers to examine data collected for other purposes to find the answers they seek to research questions. Many types of secondary data that have been collected and analyzed for other purposes are often available for re-analysis. In secondary analysis, further analysis of existing data (typically collected by a different researcher) is conducted. The intent of secondary analysis is to use existing data in order to develop conclusions or knowledge in addition to or different from those resulting from the original analysis of the data. Secondary analysis may be qualitative or quantitative in nature and may be used by itself or combined with other research data to reach conclusions ("Analysis of Secondary Data", Research Starters eNotes.com, Inc. eNotes. com, April 16, 2019).

The researcher has conducted expert interviews as well as a group discussion and took first hand opinion and responses from convenient sources like scholars, psychologists and professionals to collect the primary data on the subject which is a matter of today's concern. The term primary source is used broadly to embody all sources that are original. Convenient Sampling is a type of non-probability sampling that focuses on a sample that is easy to access and readily available (Neil J. Salkind, 2010).

\section{Internet addiction}

The term Internet addiction is often used to describe compulsive Internet use similar to clinically diagnosable behavioral and substance use addictions (Mitchell, 2000). In addition to Internet addiction, synonymous terms include cyberspace addiction, online addiction, net addiction, Internet addicted disorder, and high Internet dependency (Douglas et al. 2008).

Psychologists have begun considering Internet addiction to be a serious issue. The addiction, which has now been recognized as a disorder has a lot of impact on the brain and health and can even lead to depression among the users.

According to Shaw M \& Black DW (2008; p.358) “The phenomenon has got worse. We are now addicted to Internet and cannot imagine a day without it. We are more virtually present and active than in the real world. It is high time that we change it," Internet addiction has been described as "excessive or poorly controlled preoccupation, urges, or behaviors regarding computer use and internet 
access that lead to impairment or distress." With the ability to access the Internet from anywhere, at any time, paired with the enormous variety of Internet activities in which youth engage (e.g., social networking, chatting, streaming videos, playing games, watching television content), instances of problematic Internet behavior have emerged.

\section{Are You Addicted?}

Many studies show that if you spent two or more than two hours in a day on social media, you may have complaints of depression and irritation. You will feel mental sickness. You would not be able to face the problems of real life because you have a different imagination of virtual world in your mind. Despite all these behavioral changes, you will not accept that you are a victim of internet addiction. So, in this case, to check the reality and know the actual status of the addiction, one may apply the eight most effective screening formulae expounded by Young (1996).

To face the challenges in real world and to encounter the fake artificial virtual world, we may classify the change in behaviors of a victim that can be referred to as Internet addiction. During this study, in a query of a respondent that how you will come to know that this is the stage when someone has become addicted to the cyber media or internet, the work of Young $(1996,1998)$, who pioneered much of the early Internet addiction research denotes that Internet addiction is a measurable concept. Young (1996) specified eight screening criteria to classify (if at least five were answered affirmatively) respondents as Internet addicts:

1. Preoccupation or salience: Do you feel preoccupied with the Internet (think about previous online activity or anticipate next online session)?

2. Tolerance: Do you feel the need to use the Internet for increasing amounts of time to achieve satisfaction?

2. Loss of control: Have you repeatedly made unsuccessful efforts to control, cut back, or stop your Internet use?

3. Withdrawal: Do you feel restless, moody, depressed, or irritable when attempting to cut down or stop your Internet use?

4. Loss of control: Do you stay online longer than originally intended?

5. Interference with work or career: Have you jeopardized or risked the loss of a significant relationship, job, or educational or career opportunity because of the Internet?

6. Need to conceal behavior: Have you lied to family members, a therapist, or others to conceal the extent of your involvement with the Internet?

7. Escape: Do you use the Internet as a way of escaping from problems or of relieving a dysphoric mood (expressed by patients as sadness, heaviness, numbness or sometimes inability and mood swings. [according to www.medscape.com]

\section{Effects and Disadvantages of Internet Addiction}

The problem of Internet addiction is cultivated together with the development and spread of the internet. As we swiftly move into the digital age, we are becoming increasingly dependent on digital devices. From TVs and computers to smartphones and tablets, there are more ways to interact with digital technology than ever before. But are we spending too long looking at screens and if so, what effect does this have on our health?

With greater access to digital devices than any other generation before, it's only natural that people are turning to tablets and laptops for both work and play whenever they can. But when we look at an object at close range, our eyes work much harder to focus than they would if we were looking at something at a longer distance. Looking at electronic screens for long periods of time means that our eyes are constantly trying to bring the images or text on screen into focus, which can make us feel tired and drained.

Dawn Stephens-Borg for Lenstore Vision Hub conducted a survey in 2019 of 2000 parents in UK with children aged between the ages of 2 and 16 to gauge the effect of digital devices and how regularly 
children use them. The survey says that the vast amount of time children spend behind a screen each day would give any parent cause for concern. The survey found that $66 \%$ of parents were worried about overuse of digital devices, with a further $60 \%$ specifically worried about the effect that the overuse of digital devices would have on their children's eyesight. Although very rare, excessive use of digital devices can lead to more serious issues, including behavioral problems, attention deficit disorder and eye strain. This can cause issues in later life. Computer Vision Syndrome (CVS) is one potential condition, more common for adults, which may arise due to screens. The symptoms of CVS include blurred vision, fatigue, headaches, and difficulty in focusing. In addition, some people experience back, neck and shoulder pain from hunching over to look at small screens and focus on small text.

Media consumption through devices like smartphones, tablets and PCs among adults in India is expected to more than double from what it was five years ago, says a report by e-Marketer (June 2018).

Many studies have suggested that internet addiction is associated with loneliness, depression, anxiety, stress, low self-esteem and low life satisfaction and indicates many physical symptoms that include a weakened immune system due to lack of sleep and eye and back strain (Rosen, Larry D. et al. 2015). It has also been reported that addicted students are more likely to have low psychological well-being, which is comparable to our result. Research suggests that problematic internet use (PIU) is associated with decline in the size of social circle, depression, loneliness, lower selfesteem and life satisfaction, sensation seeking, poor mental health, and low family function. PIU is also associated with anxiety and stress. It has been found that paranoid ideation, hostility, anxiety, depression, sensitivity, and obsessive compulsive average scores are higher in people with high internet addiction than those without internet addiction. Studies also showed a negative impact of internet addiction on psychological well-being of students (Sachin $\mathrm{R}$ Gedam et al. 2017).
To abstain from the ill effects and disadvantages of addiction of internet, it is important to become a vigilant and critical consumer of the media. You have to restraint your internet exercises and become a literate media user so that you could use internet but internet couldn't use you. Roberts, et al. (1999) opines that if, by age seven, young people are spending over six hours a day consuming media messages, they deserve an education that prepares them to effectively and critically deal with media.

\section{Cyberfasting Technique}

There are no quick fixes to cyber addiction but to negotiate the challenges of internet addiction celebration of Cyberfasting as an occasion to be of from online was developed by Prof T.K. Thomas, Chairman, Gurudev Rabindranath Tagore Foundation, New Delhi (2017) from Mahatma Gandhi's concept of fasting for good cause. Two years back Thomas' idea of cyberfasting became a reality. He along with young volunteers of The Peace Gong, the peace communication platform of the Foundation, appealed to people all over the country to do a day's cyber fasting on the birth anniversary of Mahathma Gandhi, observed by the United Nations as the International Day of Nonviolence ( $2^{\text {nd }}$ October). There was very encouraging response and hundreds of children and youth came together to cyber fast on that day to experience inner peace abstaining from all digital media.

The term Cyberfasting is a combination of two words i.e. Cyber and Fasting. These two words have been merged with a purpose to induce a meaning of fasting from cyber media or stay away from online internet platforms. Fasting for longer periods for spiritual / religious or for different other reasons and objectives is not a new concept.

According to Urban Dictionary Cyber Fasting means taking a break from social networking sites and random time-killing online activities. To do cyberfasting avoid instant messaging, YouTube, Twitter, MySpace and Facebook etc.

Fasting is practiced for many reasons. Fasting has been practiced and promoted from antiquity worldwide as an expression of protest against 
what they believe are violations of social and ethical principles. (Kara Rogers, 2015, Fasting, Encyclopaedia Britannica).

Nick Polizzi (2014) in an article on The Sacred Science says 'If you were raised Christian, Jewish, Muslim, Buddhist, Hindu, Rastafarian, or Mormon, you're probably familiar with the concept of fasting'. The Times of India report (February 25, 2015) says that the Indian Orthodox Syrian Church has adopted an "unorthodox way" of observing lent on Easter. The Church has urged its members to observe cyber fast on Good Friday by abstaining from using mobiles, internet, social media platforms and watching TV etc. as part of lent. The Church said that it is an effort to dissuade its members from negative use of cell phones, internet and cyber world. Adding to this, the Church has launched a year long programme called 'Nervazhi' which means 'The Right Path' to dissuade its members from the negative use of media especially social networking sites.

According to Scroll.in (April 3, 2015), In addition to traditional fasting, the Kottayam-headquartered Malankara Orthodox Church of India this time also called for a "cyber fast" for a 24-hour period. The second largest faction of the ancient church of the St. Thomas Christians in India asked its more than 3.5 million laity to switch off their mobiles, computers and even TVs for a 24-hour period starting Thursday $6 \mathrm{pm}$ till the end of the Good Friday service. The church is doing its best to instill better values among the new generation, and tackling the cyber world is one. The Church says, "In the modern world can anyone think of not having a mobile in one's hand. A new word has been coined for it - 'nomophobia' (no-mobile phobia).

The Malankara Orthodox Syrian church has their own perspective on cyberfasting. They connect this idea with media literacy. They say that cyber addiction has been influencing the young generation. Cyber Fasting is a part of the initiative to liberate those who are over dependent on modern media tools. This will help them unshackle themselves from the negative impact of social media and have balanced media literacy. (The Hindu, February 26, 2015). Media literacy is very important; it means how each one can use the media tools without their negative impact like cyber addiction.

Cyber fasting means refraining from all types of digital media with which we are obsessed. It could be for a specific period of time. Many of us do fast on various spiritual occasions or give up certain things which we love or can't live without for a certain period. As the cybermedia is one such thing, it would be desirable to abstain from it for a day or so. Mahatma Gandhi's idea of fasting that preached cleansing of our body, mind and soul which cannot be limited to one day in a year. Mahatma Gandhi had written about the need for listening to our inner voice and about being still and meditative. We know Mahatma Gandhi's fasts were for self-purification. Fasting gives us the time to introspect and look at our inner self. Once Gandhi Ji said that, "my religion teaches me that, whenever there is distress which one cannot remove, one must fast and pray". (Young India, 25-9-1924.).

In the interview with the author, $\mathrm{T} \mathrm{K}$ Thomas suggested that during the day of cyberfasting we could abstain from using all kinds of social media and refrain from using the cyber media which can disturb our inner peace and can even bring distress. To do cyberfasting, you don't need to go anywhere or attend any event to practice. During this time, think of something you can go and do for somebody in need. Fasting rejuvenates the body, the mind and the soul by spending time with yourself. So surely Cyberfasting would help you to reinvent yourself.

In addition, Thomas also states that this could be a challenge to keep away from these forms of communication which have become integral part of our daily lives but definitely not impossible to do without. This time of cyber fasting should be time to introspect and reflect on our inner self. We could also during this time go out and volunteer for some community service. The idea of cyber fasting aims to promote 'nonviolent communication and nonviolent volunteer action, experiencing inner peace and results of introspection'.

The goal of cyber fasting is to de-addict your life and reduce any unhealthy drain on your time and energy so you are more connected to and 
productive in the real world, ideally making some people happier and healthier who seem addicted to the internet. It can make you more focused and productive.

Cyberfasting, the experience shows make people aware and understand about the negative impacts in behavior and ill impacts on cognitive abilities because of internet overindulgence. It helps realize that virtual social life should not kill our actual social life. The most important objectives of cyberfasting are to improve media literacy, rational use of digital media platforms and digital peace.

Generally, Cyber Fasting was introduced on a specific day and for the day. It is the challenge to stay away from gadgets and technologies specially from mobile and internet for whole day and continue the same at a regular interval. More than the interest of searching on internet something constructive, psychologists accept that internet addiction is an issue of psychological disorder. The researcher's hypothesis is it can be cured by practicing little but regular cyber fasting. To control our behavior patterns and addiction to internet, the researcher was in search of acceptable permanent solutions which can be practiced daily. A survey was conducted and discussion with the internet users held on 'Substantial Solutions to Internet addiction and Opinions on Cyber Fasting'.

From April 14-18, 2019 a survey among 50 internet users and on April 19, 2019 a discussion was held with 30 young frequent internet users aged between 17-25 years. All these respondents were contacted from nearby places where the researcher resides and they came from diverse socio economic background. 10 frequent social media users and media professionals also have their contribution to construct the solution which is being placed here:

\section{Findings from the Survey}

The survey was conducted with an open-ended questionnaire among 50 internet users having their own smartphones. Following are the responses:

1. 6 respondents shared that they do not sleep at night without watching online/offline porn videos. All these respondents are unmarried.
2. 20 responses show that people used to talk with their loved ones (mostly boyfriend and girlfriend/wife \& husband) immediately before they go to sleep.

3. 15 youngsters have a tendency to chat online with their online virtual friends (it includes friends from abroad) who are not physically known to them.

4. 9 responses show that people used to do trivia online or watch movies, news, cricket or spiritual, learning or funny videos to kill the time till they sleep.

\section{Excerpts from the Discussion}

Many of the respondents were not interested and were hesitant in disclosing the facts of using frequent internet. They did not want to declare that why they use and spend so much time on smartphones. I requested them to show their mobile phones to me to check but many of them refused. Some of them have tried to boycott the discussion but on my request and assurance that their phones will not be checked they joined back. I offered them tea and after some gossip over tea, they became familiar and one of the respondents started to open his secrets. He said, I don't want anyone to touch or use my mobile phone because there are many things inside it which will uncover my bad side. I curiously showed interest to know about those things. He said there are some contacts in phonebook which are of my girlfriend/s, many photos with them are in gallery; there are number of porn movies in phone; number of websites are opened having adult and abusive content; in WhatsApp there is private chat with my girlfriends and other friends; many Facebook friends are unknown; many of them are from abroad and I used to chat with them at night'. More or less the story was the same of about 10 to 12 respondents. 6 respondents told that they do not keep adult content in their mobile phones but whenever they want, they would go online for the adult content (videos, sext (text on sex). Other respondents are keen to play games on mobile phones and chatting on WhatsApp and Facebook instead of watching bad things online or offline. The researcher asked them a question- what 
do you get from doing all these trivia on mobile phones and internet. Common answer from all the respondents was 'nothing'. Zero income, zero output and zero satisfaction. They said, they know that these things are wrong; they know that by doing trivia on smartphones and internet, they are wasting their non-refundable precious time of their young golden age, energy of doing something creative and productive and most importantly, they are losing their relations.

During the discussion, one thing was established that people addicted to internet and smartphones are not satisfied with their devilment and weird nature. It is a kind of mental problem because they did not have something more important to do. It means that whenever they are free they go for their mobiles instead of talking with their family member or doing self evaluation. To find solution for this sickness, the researcher carried forward the discussion with some ideas which were originated from the inputs given by media professionals and senior social media users, with the hope of initiating de-addiction.

\section{Recommending Solutions from Research Findings}

A survey with 50 respondents and a FGD is not adequate for a clinical prescription. However, the insights from both are shared below for further testing.

As any doctor suggests minimum three doses in a day to be cured from an illness, three doses of cyber-fasting in a day can be a substantial solution for internet addiction. With initial inputs placed by the researcher among the discussants, some interesting ideas have emerged which would be helpful in preventing our precious time and mental consciousness. It was a common opinion of the group that following these tricks may save minimum of five (5) to six (6) hours in a day from doing trivia on different media platforms. With the help of following suggestions we may find peace in our inner world as well as digital world. After assimilating these tricks, we would be able to use cyber platforms more effectively than ever before.
This can give us enough time to think over that how to use and why to use these media platforms. These are three simple tricks everyone can follow:

1. Do not see any screen at bed-time in night: It will be very helpful if you do not see any screen (Mobile, TV, Computer or Laptop etc.) and do not use internet a minimum of one hour before you go to bed in the night. Spend those precious moments at your home with your family members. Talk to your wife and children; have an evening tea with your parents and family friends, go for a walk on your roof and feel the nature. Live every second blithely. By doing this, you will save your physical and mental health and most importantly your relationships.

2. Stay away from Digital Equipment till your Breakfast in the Morning: Try to be a committed person and develop a habit of living without mobile phones and TV or any screen during morning time. Make a commitment with yourself that you will not touch your mobile or TV (unless it is really necessary) till breakfast. You will spend your morning time with your family members and not with TV or mobile.

3. Never see any screen while Eating: Most commonly in today's lifestyle, we are used to have food thrice in a day i.e. Breakfast, Lunch and Dinner. And at every meal we spend a minimum of half an hour to one hour. This formula of not watching any screen while having food will save at least two hours in a day. Ms. Manju Aggarwal (Naturopathy Consultant) says that according to Ayurveda, our two eminent Rishis, Maharshi Charak and Acharya Sushrut considered food as medicine. It heals our body and mind, energize our organs, abolish bad bacteria, enhance immunity and construct a space for peace in mind and body that generates positive thoughts. So, as we consider our food as 'Aushadhi' or medicine, we must assure that during the time of having food, we will only focus on our food. It will give you space to stay with yourself, to talk with yourself and to connect with your eternal divine soul. 


\section{DISCUSSION}

Fasting is the greatest remedy. Ancient Greeks believed that fasting improves mental and cognitive abilities and can solve problems better during fasting (Monica Stapleton Feb. 2018). Cyber addiction creates virtual world but also promotes physical isolation and loneliness in users of cyber media platforms. The very popular game of Blue whale is one of the examples from the recent online/ mobile games which only created isolated world for the players and many people became victims of this killing game.

Fasting can heal body and relax mind, create positive thoughts and aura around you. Fasting is a deliberate and conscious choice and practicing fasting provides an environment to think over practical aspects of life and constructive investment of every moment which brings inner peace and creative skills of self-assessment and helps in taking sensible decisions.

According to the study based on discussions with the experts, Fasting from using cyber media can be one of the methods, to dissociate from cyber platforms and to move forward for constructive actions.

There are many examples that prove fasting as a strong method which leads towards positive thinking and constructive work. For Mahatma Gandhi fasts were significant to look at one's inner self. Mahatma Gandhi in Young India (03-12-1925) says "Fasts are a part of my being. I can as well do without my eyes, for instance, as I can without fasts. What the eyes are for the outer world, fasts are for the inner".

An optical expert Dr. Rob Hogan, a registered optometrist for over 33 years, opines his thoughts on screen time before bed, "It is important to limit access just before bedtime, as research has found that the background 'blue-ish' light typically emitted from these devices can disrupt normal sleep patterns. Also, blue light chronically absorbed throughout life is implicated in Age-related Macular Degeneration (AMD), increasingly found in later life." Dr. Hagan suggests, the 20/20/20 rule which means for every 20 minutes spent on a digital device, spend 20 seconds looking at something 20 feet away.

Dr. Alok Mishra, an expert in Brain Behavioural Changes says that the evil habit of internet addiction is more intoxicating than smoking and alcohol intake. It kills emotions and decreases the sympathy level in a human being. Victims of cyber addiction always assume the virtual world as a real world, which will be their living planet. This symptom minifies the power of confronting real life challenges. The social media addiction will not turn them into an orator or a successful achiever of their life goals. They will throw away themselves in the trivia on social media and fake life hero in video games and will lose the precious opportunities of becoming real life hero by spending their time with their loved ones. They will feel themselves safe and comfortable in that virtual zone only because whenever required they can escape from virtually created tough situations or they can find an easy way or excuse to escape from. This symptom increases fear of fighting with real life hurdles which are far different from virtual ones. One should understand the necessity of detachment from cyber places at the nick of time.

\section{CONCLUSION}

The objective of this paper is to promote digital literacy and peace and providing possible solutions to de-addiction from cyber media. In the words of Thomas, 'We live in a digital world. Every moment of our life, right from the time we wake up to the time we sleep in the night we are engaged with some digital platform or the other. By recommending the above mentioned path to internet de-addiction, Thomas repeats his appeal with the questions, "can we think of giving up our digital tools for some time and do introspection of our own self? Can we think of the time we spend on the digital media and instead spend that time to help at least one of the needy persons in the society? (T.K. Thomas, 2018).

\section{REFERENCES}

Analysis of Secondary Data; http://www.enotes.com/researchstarters/analysis-secondary-data\#research-starterresearch-starter 
Christine Suniti Bhat, Shih-Hua Chang and Jamie A. Linscott, 2010. Addressing Cyberbullying as a Media Literacy Issue, New Horizon in Education, 58(3).

Constantinos C. Frangos, Christos C. Frangos, and Ioannis Sotiropoulos; 2012. A Meta-analysis of the Reliabilty of Young's Internet Addiction Test (retrieved on March 16, 2019 from http://www.iaeng.org/publication/WCE2012/ WCE2012_pp368-371.pdf)

Deborah. G. Grady et al., Research Using Existing Data retrieved on April 16, 2019 from https://pdfs.semanticscholar. org/343e/04f26f768c9530f58e1847aff6a4e072d0be.pdf

Einar B. Thorsteinsson, 2017. Internet Addiction, Psychological Distress, and Coping Responses Among Adolescents and Adults Published Online:1 May 2017https://doi. org/10.1089/cyber.2016.0669 retrieved on March 16, 2019.

Jessicla Dillinger. A List of Countries by Internet Users (2019) retrieved on April 22, 2019 from https://www.worldatlas. com/articles/the-20-countries-with-the-most-internetusers.html

Kara Rogers () Fasting, Encyclopaedia Britannica (retrieved from https://www.britannica.com/topic/fasting)

M. K. Gandhi; Young India, 25-09-1924, p.319.

M. K. Gandhi, Young India, 03-12-1925, p.422.

Monica Stapleton (2018), Famous Fasters from the Past (retrieved from https://fastingfridays.org/famous-fasterspast/ on 20 April, 2019).

Nick Polizzi, (2014) Jesus did this, Buddha did this, Muhammad did this. Article retrieved on April 15, 2019 from https://www.thesacredscience.com/jesus-did-thisbuddha-did-this-mohammed-did-this/

Neil J. Salking. 2010. Encyclopedia of Research Design, Sage.

Orthodox Church to observe Cyber Fast' https://www. thehindu.com/news/national/kerala/orthodox-churchto-observe-cyber-fast/article6935306.ece (retrieved on February 25, 2019)

Rosen, Larry D. et al. "Social Networking is Addictive and Can Lead to Psychological Disorders." Are Social Networking Sites Harmful? Edited by Noah Berlatsky, Greenhaven Press, 2015.
Sachin R. Gedam, Santanu Ghosh, et al. 2017. Study of Internet Addiction: Prevalence, Pattern and Psychopathology among Health professionals undergraduates (retrieved from http://www.indjsp.org/ article.asp?issn=0971-9962; year=2017; volume=33;issue=4 ;spage=305; epage $=311$; aulast $=$ Gedam;aid=IndianJSocPsy chiatry_2017_33_4_305_218605 on April16, 2019

Salman S.H. 2018. Media consumption via digital devices among Indian adults to more than double: Report retrieved on April 25, 2019 from https://www.livemint. com/Consumer/Xm9BKozx0OihvWDD8HXa7O/Mediaconsumption-via-digital-devices-among-Indian-adultsto.html

Seog Ju Kim, Doo-Heum Park, Seung-Ho Ryu, Jaehak Yu \& Jee Hyun Ha, 2012. Usefulness ofYoung's Internet Addiction Test for clinical populations (retrieved on March 16, 2019 from https://www.tandfonline.com/doi/ abs/10.3109/08039488.2012.748826?journalCode=ipsc20)

Shaw M. and Black D.W. Internet addiction. CNS Drugs 2008; 22:353-365. Crossref, Medline, Google Scholar.

https://www.indiatoday.in/mail-today/story/gandhi-jayantipeace-gong-cyber-fasting-internet-addiction-10560462017-10-02Retrieved on April 16, 2019

https://timesofindia.indiatimes.com/city/kochi/OrthodoxChurch-calls-for-cyber-fast-on-Good-Friday/ articleshow/46363850.cms (retrieved on April 16, 2019)

https://scroll.in/article/718083/good-friday-from-carbonfasting-in-mumbai-to-cyber-fasting-in-kerala (retrieved on April 16, 2019)

http://hepeacegong.org/wp-content/uploads/2019/01/ The-Peace-Gong-Initiative-on-CYBERFASTING1.pdf (retrieved on April 16, 2019)

https://www.livemint.com/Consumer/Xm9BKozx 0OihvWDD8HXa7O/Media-consumption-via-digitaldevices-among-Indian-adults-to.html(retrieved on April 16, 2019)

https://www.marketwatch.com/story/people-are-spendingmost-of-their-waking-hours-staring-at-screens-2018-0801(retrieved on April 16, 2019) 
